\title{
ORGANIZATIONAL THEORY, SYSTEMIC THINKING AND SYSTEM MANAGEMENT
}

\author{
Shahram Mirzaie Daryani ${ }^{a^{*}}$, Samad Ali ${ }^{\text {b., Ahmad Asli-zadeh }}{ }^{\mathrm{c}}$ \\ a. Islamic Azad University, Ardabil branch \\ b. Islamic Azad University, Tabriz branch \\ c. Islamic Azad University, Shahr-e-Rey branch
}

\begin{abstract}
Organizational theory, as a field of study, offers to those interested some effective ways of thinking. This knowledge helps managers make organizational behavior more efficient through analyzing complex situations and developing effective tools to resolve them. In other words, it opens human mind to different aspects of life inside and outside the organization. Therefore, the value of organizational theory is in changing managers' thinking ways, thought patterns and performance. But a fact should also be considered, that organizational theories, affected by the passage of time and existing changes, have transformed and become variant, thus have not been always neatly compatible with one another. To the extent that, some scientists have considered this situation as a shaky foundation for a scientific discipline. In the same vein, the present paper investigates systemic thinking as a new knowledge of organizational theory. The literature indicates that knowing this thinking is essential and it triggers change in people's thought and attitudes, as such, organizations' management, i.e., systems' management becomes more effective. But through more reflecting, it can be apprehended that this knowledge is accompanied by some contradictions and complexities that harm its coherence and scientific message. This situation requires wisdom, reinvestigation and reform.
\end{abstract}

Key Words: organizational theory, systemic approach, contradiction, complexity, system management

\section{Introduction}

A theory is based on a set of presumptions which forms the basis of a number of related but logical claims. Some theories assume that fact is objective (out of researcher), while some other assume that the fact is subjective (within the researcher). Objectivists believe that since the fact exists out of the researcher, it can be studied by observers who are independent of the issue under investigation. On the contrary, subjectivists claim that since reality is within the researcher, it is personal and relative.

\footnotetext{
${ }^{*}$ Correspond author
} 
Hence, independent observation is impossible. They argue that since knowledge is attained via some mediums, it drastically changes through observation. Thereupon, different assumptions lead to different theories. Due to such differences, identifying assumptions which underlie a specific theory is of high importance. A special phenomenon that a theory explains is called the phenomenon under investigation (Hatch, 2006) and (Hatch, 2012).

In the organizational theory, the phenomenon under study is organization. Organizations can be defined in different ways: as a social structure, a technology, a culture, a physical structure or as a part of an environment. Organizations can be studied on pivotal controversial issues such as supervision, contradiction, decision-making, power and policy, and change. Therefore, theory is formed depending on one's view to organization (Stoner et al., 1995) Due to variety and pluralism of organizations, managers should be able to give sense to and apply different views, and should learn how to use their knowledge in the wide range of daily decisions. The point is that systemic thinking, as one of classifications of and approaches to organizational theories, enables managers to be successful and effective in their duties, roles and responsibilities. But as it is applied, do they recognize its obscurities and contradictions? How do they interpret these contradictions and complexities? Ultimately, how much do they benefit from this thinking?

\section{Classification of organizational theory from the scholars' point of view}

Harold Koontz [1] in an initial classification of organizational theory mentioned six schools: 1) management process school, 2) empirical school, 3) human behavioral school, 4) social system school, 5) decision-making theory school, and 6) mathematical school. Nineteen years later, he increased the number of levels in this classification to eleven levels, which was not welcome due to overlaps among levels and triviality of levels. Williak Scott (Hatch, 2012) has mentioned three schools in organizational theory and management: Classical school which deals with division of labor, hierarchy, supervision, and logical structure, neo-classical school which is known by human relations movement, systemic school which defines organizations as systems with mutual relations among internal parts and variables dependent on environment. He has placed the last school on a higher level than the two previous ones. Richard Scott (3) has divided organization and management theory into four groups. His criterion in division was open and closed system view to organization and rational and social models of human behavior in organizations. In theory of the first type, organization is regarded as a closed system, and human behavior is considered rational. Theories of scholars such as Taylor and Fayol fit into this category. In this view, organization is a means to achieving predetermined goals, and the relationship between organization and the external environment is not taken into account. Clear objectives, defined duties, exact organizational hierarchies, and rule-governedness are the cornerstones of thought of this category. Meeting material and physical needs to attain efficiency are emphasized. In theory of the second type, humanism, organization is considered as a closed system and the behavior of humans is social. Theories named "human relations" belong to this category. Elton Mayo, is the pioneer and main figure of this theory. Meeting affective and social needs is the main action to be taken for increasing the performance of organization members. In the theory of the third type whose origin dates back to 1950s, organization is considered an open system, and the behaviors are assumed rational. In this category, an effort is made to form organizational structure while keeping environmental needs in mind. The theories of Thompson, Parsonz and Woodward pertain to this category, and are called contingency. Put simply, they tried to match management with contingencies and environmental conditions, and take it away from absolutism. The third type is formed adopting an open system view and attributing social nature to organizational behaviors. Ideas of some scholars such as Mayo, Rwan. Salan Sick, and Paufer are of this type. Based on the theoreticians' ideas in this category, to evaluate effectiveness of organizations, one cannot rely 
on only visible, nonpolitical social criteria. But the issue should be studied and evaluated as a social and natural behavior in a political context. Views of theoreticians in this category are also considered contingent.

Hatch has drawn the trend of historical changes of organization through an academic pedigree. He points that since organizational theory did not rise as a formal field of study until 1960s, the classic period is part of the period prior to the history of organizational theory. On this basis, Hatch explains classic management and its role in organizational theory, and focuses on explaining modernism, symbolic < interpretivism and post-modernism as parts of organizational theory. Hatch

believes that general theory of systems has affected a large part of the modern approach to organizational theory. General systems' theoreticians have been able to focus on fundamental unifying similarities of all phenomena. Therefore, general theory of systems, as a revolution in guiding science, paved the way for inter-disciplinary researches, and along with cybernetic science it became a basis for the rise of systemic thinking.

Following Richard Scott, Tosi (3) categorized organizational theory in four types: wise paradigm of closed systems, paradigm of open systems, natural paradigm of closed systems, and natural paradigm of open systems. The rise of systemic thinking is related to wise paradigm of open systems, and its reform is related to natural paradigm of open systems. Sterner, Freeman and Gilbreth (Hatch, 2012) refer to six levels in the trend of reform of management theories: scientific management school, behaviorism school, science of management, systemic perspective, contingency perspective, and dynamic challenge perspective. These scholars ascribe the rise and formation of systemic thinking to the influence of general theory of systems.

\section{Systemic Thinking}

From theoretical viewpoint, it is rational for these theories to have multiple common aspects. They are about organizations and often have their roots in positivism. The main difference among them is that each theoretician, in his/her effort to know the organization and make it efficient, makes use of different principles. The aim of the present paper is to investigate the concept of and essence of systemic thinking, not in comparison with other theories, but highlighting it as solitary concept. As it was mentioned before, a theory (4) is an artifact of human. It is an abstract way to express facts, through presenting a definition out of a set of concepts, definitions and theorems which regularly have mutual relations with each other, and these relations show the features of the fact. Are the views of scholars consistent with each other in systemic thinking? To understand systemic thinking and apply it, i.e. system management, first one should get familiar with definitions of system as well as its fundamental concepts such as classification and features of the system. Then the three stages of systemic thinking should be understood and put into practice. At the same time its rules needs to be understood and applied as well. In the following, we will respectively investigate definitions of system, its characteristics, the three stages of systemic thinking and its rules along with contradictions, complexities and existing ambiguities.

\section{Definitions of system}

Similar to management, many definitions has been provided for system. Some of definitions are presented below (Tosi, 2009; Senge, 1990; Sterman, 2000; Mar-ashi et al., 2010 \& Ghobadi, 2007):

- System is a whole whose life is possible through establishing mutual relationships among its elements (Bertalanffy)

- System embraces a series of concepts or factors which are employed for meeting a need (Miler) 
- System denotes disciplined and clear planning (Johnson).

- System includes mental or physical entity which is made of dependent elements (Bakt).

- System is a set of various processes in which cause and effect relationship can be found (Wat)

- System is a group of interrelated factors that receive input from environment, then transfer them, and finally sends output to the environment (Daft).

- System has transaction with the outside world as an entity (Feller).

- System is anything that gains its form and totality from interaction of its constituents. Its elements have common goal and act in similar way and these elements are interacting with each other (Sange).

If we inspect this definition, despite the stress of scholars on internal relationship one can come up with terms and concepts which are not mentioned in other definitions. Do other definitions have such absolute clarity speaking about elements and parts? Are these interacting processes the same interacting elements and parts? Is human a part or the process itself? Furthermore, in most of the definitions there is no mention of the relationship between system and environment.

Although Ikaf in his definition has made an effort to provide an illuminating insight of system, two more points deserve consideration: First, in any knowledge, the fewer common concepts are, the more their interpretability is. Hereupon, understanding and implementing them are unclear.

Second, a question about the concept of part arises: What is meant by part? Does it mean human? Processes? Microsystems? Resources? or even subjective interpretations like knowledge and quality?

\section{Characteristics of system}

Mar-ashi et al. (2007), Rezaeian (2010) and Zahedi (2010) have referred to the following features in systems: goal, elements/constituents, relations, environment, resources, state, hierarchy, and complexity. The nature of some features requires further investigation. Some points were discussed about elements and ambiguities. In exploring environment in terms of internal and external space of system, the need for bordering system can be recognized. Defining and characterizing border is a case that is not possible and scholars have emphasized it. Thereupon, identifying the internal or external factors can be area of debate for systemologists. Such an insight may provide not precise specification of the factors affecting behavior and performance of system in the condition that the two types of internal and external environments are intended to be investigated.

Hierarchy is based on system and microsystems. The microsystems themselves involve other sub-microsystems and this trend continues. As each system is comprised of inputs, processing, output, feedback, and environment, making distinction among these five parts of system and microsystems' structure and accepting their limits, to what extent is it possible to suppose such a structure for the main system and it's consisting microsystems in the hierarchy?

The message of the following sentence deserves more attention and requires more inspection: "the difference between systems and subsystems is completely theoretical, because it entirely relies on the situation of system" (Hatch, 2012). In other words, making distinction between system and microsystems rests on how the system under study is defined and what aspect of it is intended. As such, every supervisor, or counselor of system's affairs, or system management can vary from others in identifying, analyzing, and removing barriers. Of consequences of this behavior is the problem of evaluation of methods implemented. Can this behavior be a sign of contingency management? It seems that obscurity of hierarchy makes different tastes appear and it is not equal to contingency management.

\section{Systemic thinking and three stages of problem solving}


There are abundant evidence related to systemic thinking theory (Hatch, 2006; Hatch, 2012; and Sushil, 1993) that suggest three following stages for examining and dealing with problems:

1. At first the whole system including above mentioned point should be identified

2. Subsequently behaviors and features of whole system should be characterized and investigated.

3. Ultimately the behavior or characteristics of subject under study should be analyzed in respect of their parts or functions in the whole system.

The following cases are presented as examples:

- Examining the lack of incentive in human resources in an organization

- Exploring reasons for success of a company in the area of creativity and innovation

- To scrutinize why students studying in different grades quit schools or college in one of the provinces. Examining the process of presidential elections in one of the states.

To exploit three stages of systemic thinking in solving such problems in each of four cases depending on the point of view that an analyzer, the organization's systemic affairs counselor, and managers themselves with a variety of tastes hold, the entire system can be defined. In the case that the whole system is characterized, how much information can be gained for investigating the behaviors and the features of entire system. If the possibility of gathering information is equally possible for everybody, regarding the point that we referred to mutual relationship and interaction among the elements of system in defining system, will the subject under study, which is doubtlessly a micro-systemic problem,ìbe affected by other microsystems? Although these microsystems are definitely influencing

each other, in the three stages pointed out above there is no referring to this important issue. However, it is emphasized that, admitting these three stages, to be employed in solving any intended problem this method is as microsystem. Ultimately, another vague idea according to definition of system relates to the point that these parts are microsystems that via interacting with each other offer a particular entity to the main system. As it was referred above, a subject or a problem was taken as a microsystem without identifying other microsystems and the result of their interaction as a whole. How an entity can be identified according to the first step? If we reflect upon the third item of the three steps the relationship between microsystem and main system has been pointed out. In other words, there is no reference to interaction among microsystems the ambiguous point which was discussed before.

\section{The rules and principles of systemic thinking}

In most of systemic thinking sources (Stoner, 1995; Tosi, 2009; Sushil, 1993) the rules and principles of systemic has been listed under the following headings mentioned below:

- Focusing merely upon happened events and their causes should be avoided; rather the patterns of changes should be discerned.

- System problems mainly need to be examined internally rather than externally, and the environmental conditions shouldn't be reprimanded.

- What holds true for each member and part of system can not necessarily ring true for entire system.

- The best way for characterizing phenomena is determining relationships among its constituents.

- The effect of structure of system on performance of its parts is more than the effect of performance of its parts on structure of system. 
- Procrastination in any issue and to any extent is considered as kind of wasting and reason of entropy; therefore it must to be removed.

- Discovering cause and effect relationship among variables and phenomena and even much more important than it is finding correlations among them.

- Defining accurate boundaries for system results in making sensible decisions.

- Dynamic thinking can explore more effective ways for solving problem than static thinking.

- Adopting disastrous policies entails social systems’ invisible behaviors.

Delving into these principles and rules, it can be noticed that there is a clear and in some cases invisible relationships between them and system characteristics which were mentioned before. Inspecting the ties between parts and processes of a system, given they are identified properly, provides us with insight about the pattern of gradual changes and prevents us from dealing with the occurred incidents. If the internal relationship is discerned, synergy can be achieved and the entropy can be pushed toward negative direction. In this case the reason for problems inside the system can be found. While examining the problems and phenomena, and exploring reasons, one can come up with solution for reducing entropy or taking advantage of opportunities in optimal size. If in making decisions comprehensive solutions/approaches are taken, less amount of individuals' invisible behavior and their resistance will be faced. In spite of these principles and effective points, there will be still some contradictions and obscurities. How should the causes of the system problems be mainly identified? Internally or externally? Why a person doesn't progress? Why the work groups don't function successfully in the organization? Why does an organization face bankruptcy and crisis? Why does a country suffer natural disasters or trade, military and economic crises? Should the reasons for such chaos be internally explored?

Most of system theoreticians believe in what was discussed in the structure of system indicating that there is a steady relationship between a system and its environment and they mutually affect each other. The educational environment can play role in the individuals' failure. And lack of careful and detailed evaluation of groups' performance results in their inefficiency. War, economic sanction and various and interpretable rules have major part in driving organizations into bankruptcy. The geographical position of each country can be affected by natural disasters in that region. Each of these systems can be under influence of environmental events. On this basis it cannot be certainly said that the problems of system should be mainly evaluated internally. There is area of ambiguity around further effect of structure of system on performance of parts compared to effect of constituents' performance on the structure of system. The definitions of system indicate that the interaction of the system parts can display a special characteristic of system which is called "whole" in general term. Thus, each system with its own specific wholeness as its identity can be recognized. Now the question that can be put is: In the case the structure of system carries the title of overall state of a system how can the effect of a system structure on behavior and performance of a part take on significance? In other words, the sum of interactions among the parts of system brings about wholeness. However, the effect of structure as a whole on its parts is more considerable than the inverse form of this relationship. Furthermore, if structure of a system has something to do with organization and its relations, unquestionably affect individuals' performance, but this phenomenon in the reversed direction rarely occurs. It has been seen that a worker, a manager, or an employer could have been able to respectively produce dramatic change in the process of quality and production, plan fundamentally, and tackle crisis. Besides, the influence of an author and politician in shaping political and social evolutions in countries is a remarkable phenomenon. The failure and stop of a machine in a manufacturing company most often than not can be crisis provoking. Henceforth, the effect of a part on whole shouldn't be considered insignificant. The holographic principle in systemic resources 
(Tosi, 2009; Murthy, 2001) is in contrast with the principle of continuous interaction of parts and formation of wholeness principle. If a mirror is broken into pieces, each piece like the initial unbroken mirror can reflect the image; this presented example can explain the principle.

Accordingly, this state of the system can be adapted to the structures, or units that can act like the basic unit or structure. Definitions and descriptions of the system show that all the scholars have consensus upon: First, constant communication of parts causes the whole. Secondly, if an organization is divided into microsystems, will the microsystems represent the entire organization? Believing in designing interactional patterns (Tosi, 2009; Najaf Beygi, 2011), does not always show the transparency and clarity of action. An observer in stating her/his major insights and perceptions considers the unceasing relationship and ignores the algorithmic, process, initial and final form. For example, in the systemic learning organization of Marquardt (2002), the weighting of the components has not been carried out, and it seems that the components are of equal weight and significance.

Finally, the scholars' perception and at times the incompatibility of such perceptions are of the issues which require contemplation in systemic thinking. Chris Murphy (2001), referring to the following principles introduces systemic thinking:

- Emphasizing development and growth in every aspect

- The necessity of considering/creating a reasonable prospect

- forming unification/union and unity

- developing systematic emotions/feelings with sense of peaceful coexisting with nature

- Feeling respect and holiness, avoiding self-concerns

- The compulsion/exigency of leadership in organizations

Hatch (2012) also refers to advantages of systemic thinking as follows:

- More influential method about thinking system, goals, environment, and its parts

- Framework and method for ginning insight into complexities of life, (because every live being is considered as a system).

- A method for learning of new ways in an easy way and unifying basic rules of systems.

- Creating a framework for identifying, analyzing, and solving problem and making decision in the system (which entails the easy understanding of complex issues, such as the interaction of parts in the multiple cause and effect cycles)

- a method for complexity management in the era of systems through accentuating each part and their internal relations

- A method for observation of whole system along with observation of its constituents

- A prospect for discerning short and long-term consequences

Making a comparison among different perceptions of systemic thinking with mentioned rules obtained from beliefs of some of system theorists, one can hardly ever come up with noteworthy common points. Such differences results in mental, behavioral, and functional dispersion, utilizing it. 


\section{Conclusion}

Systemic thinking has been proposed as one of the organizational theories and management approaches, and implemented by exploiters. This thinking has broken/ignored some traditional paradigms and opened up a new window of perspective to users. Of the main effects of the thinking are the evolutions in the mental models and developing problem-solving methods at a micro or macro level in the human societies. System dynamics and causal loop diagram, expanding the concept of feedback, complexity management, chaos theory, environmental issues can be ascribed to development of systemic thinking. From one perspective, conflicting interpretations and perceptions, and from realistic point of view, contradiction in some concepts of this approach, gives priority to reviewing and correcting/modifying such ideas. Managers and leaders can utilize systemic thinking in the case that they take the part of an effective theory in the organization's life and its accomplishments and conceptualize terms and expressions and make attempt to understand the cohesion, and internal consistency, i.e., its validity.

Digging deep into this theory, the following vague and conflicting issues were identified:

- Disparate definitions with little commonalities

- Obscurity of the parts borders and sources as features of systems

- Changing systems into microsystems and vagueness of inputs, outputs, and internal or external of microsystems.

- Making use of three stages of problem solving adopting systemic method although noticeably unclear systems' change into microsystems beside vagueness in systems boundaries

- placing emphasis on recognition of systems' (organizations) problems more internally and less externally (environmental effects)

- taking the effect of system's constituents on its structure as no apparent

- The contradiction of holographic concept and entity

- the insistence of systemic models on adopting interactional view about their parts, and not proceeding in a step by step and algorithmic way

In recognizing problems of systems including organizations and humans, in addition to these ambiguities that each of them are mentioned as one of basic methods for solving systemic problems, there are obstacles against discerning and employing systemic thinking in our society such as :

- Humans are mesmerized by their own mental models and frameworks which are part of themselves, such a basis, unconsciously, turns into a hindrance against admitting systemic thinking; because it is a difficult task to avoid such frameworks and models in examining topics and events, without prejudice and relying on old patterns.

- The second barrier stems from the prior one. Inasmuch as live and perform in the reality, every person carries experience based on practice. These experiences, in turn, change the attitude toward subjects and phenomena. Accordingly, humans instead of considering themselves as creator of phenomena, tend to respond to them.

- The essence of systemic thinking requires attending to relations not subjects and objects, while individuals are accustomed to heeding objects and tangible matters. In fact, only once it becomes possible to observe and analyze relations that a lot of effort is made on the part of the individuals.

- The fourth barrier in opting for systemic thinking emanates from the humans biology and their survival instinct. This instinct can overcome observation: intuition and reflection which are 
sine qua non of systemic thinking. Therefore, such thinking can remain at the level of mere yearning and curiosity, and choosing and implementing it becomes a tough task.

\section{References}

Ghobadi, SH. (2007). System dynamics, as an application of system thinking, industrial management institute (in Persian).

Hatch, M.J. (2006). Organization Theory, available at: http://www.studymode.com/essays/Organization-Theory284914.html.

Hatch, M.J. (2012). Organization Theory: Modern, Symbolic, and Postmodern Perspectives, $3^{\text {rd }}$ edition, Oxford University Press, USA.

Mar-ashi S.J,; Baligh, V.and Ghiasabadi, A. (2010). System thinking and evaluation of its effectiveness in managing organization and community, industrial management institute (in Persian).

Marquardt, M.J. (1996). Building the learning organization, New York: McGraw-hill.

Marquardt, M.J., 2002. Building The Learning Organization (2 edition), Palo Alto, CA: Davies Black Publishing, INC.

Murphy, K.K. (2001). Management philosophy for the new millennium, Allied Publishers Pvt. Ltd..

Najaf Beygi, R. (2011). Organization and management, Publishing Center of Islamic Azad University, $3^{\text {rd }}$ edition (in persian).

Rezaeian, A. (2010). system analysis and design, Samt publications, 13rd edition (in Persian).

Senge, P.M. (1990). The fifth discipline: the art and practice of learning organization", New York, Doubleday.

Sterman J. D. (2000). Business Dynamics: Systems Thinking and Modeling for a Complex World, McGraw-Hill/Irwin, USA.

Stoner J.A. ; Freeman R. E. and Gilbert D. R. (1995). Management, Prentice Hall.

Sushil, SH. (1993). System Dynamics: A Practical approach for Managerial Problems, Wiley Eastern Publication, New Delhi.

Tosi, H.L. (2009). Theories of organization, SAGE Publications, Inc, USA.

Zahedi, SH. (2011). systems analysis and design, Allameh University press, $10^{\text {th }}$ edition (in Persian). 